\title{
ENSINO DE HISTÓRIA: argumentação e construção de sentido na História ensinada
}

\section{TEACHING OF HISTORY: argumentation and the construction of meaning}

\author{
Patricia Bastos de Azevedo* \\ Ana Maria Ferreira da Costa Monteiro**
}

\begin{abstract}
Resumo
Este artigo objetiva discutir a construção de sentido através da argumentação na História ensinada, a partir de uma pesquisa de campo realizada em uma escola da rede municipal de Niterói-RJ. A pesquisa de campo constitui-se de 30 horas de gravação de aulas de História de uma turma do $4^{\circ}$ ciclo do Ensino Fundamental (correspondente ao $8^{\circ}$ ano). Na análise de dados buscou-se a articulação com elementos teóricos vinculados ao currículo, à linguagem e à cultura. Destaca-se, com tal exercício, uma possibilidade de aproximação teórica dos conceitos vinculados a esses três campos de conhecimento, relacionando-os a um espaço concreto - uma sala de aula de História. O desafio proposto é dialogar com as teorias dos campos do currículo, da linguagem e da cultura, buscando compreender a construção de sentido na História ensinada pela argumentação.
\end{abstract}

Palavras-chave: Ensino de História. Currículo. Cultura. Linguagem. Argumentação.

\begin{abstract}
The aim of this article is to discuss the construction of meaning through argumentation in the teaching of History. The field research was carried out in a municipal school in Niterói - RJ. The research included 30 hours of recordings of History classes of a group of the $4^{\text {th }}$ cycle of Elementary Education (also called $8^{\text {th }}$ year of Elementary Education). The data analysis articulated the theoretical elements related to curriculum, language and culture. It can be pointed out a possibility of theoretical approximation of these three fields of knowledge relating them to the concrete space of the History class. The challenge is to create a dialogue among the theories from the curriculum, language and culture fields, aiming to understand the construction of meaning in the teaching of History by means of argumentation.
\end{abstract}

Keywords: Teaching of History. Curriculum. Culture. Language. Argumentation.

\section{Introdução}

Neste artigo, discutimos a construção de sentido através da argumentação na História ensinada. Para isso, foram utilizados subsídios obtidos na pesquisa realizada no ano de 2003 em uma sala de aula de História. A análise feita retorna ao material investigado durante o mestrado, buscando assim revisitar algumas questões e repensá-las à luz de elementos teóricos vinculados ao currículo, à cultura e à linguagem.

O desafio proposto foi dialogar com estudiosos desses três campos - currículo, linguagem e cultura - buscando compreender a construção de sentido na História ensinada via argumentação. Usou-se, como arcabouço conceitual, o diálogo com os autores Habermas e Bakhtin, buscando estabele-

\footnotetext{
* Docente da Universidade Federal Rural do Rio de Janeiro. E-mail: patriciabazev@yahoo.com.br

** Professora doutora da Universidade Federal do Rio de Janeiro.

E-mail: anamont@superig.com.br
}

cer convergências teóricas entre eles para compreender a argumentação e a construção de sentido na História ensinada.

\section{A realização da pesquisa}

A pesquisa de campo foi realizada em uma escola da rede municipal, localizada em Niterói-RJ, no $4^{\circ}$ ciclo do Ensino Fundamental, $8^{\circ}$ ano escolar. ${ }^{1}$ A comunidade onde está localizada a escola municipal é extremamente pobre e os alunos dessa unidade escolar são oriundos principalmente de seu entorno. Além disso, o depósito sanitário desse município - o lixão de Niterói - está localizado nessa comunidade.

Quando subimos o morro, temos, à direita, o lixão e, à esquerda, uma área verde com a presença

\footnotetext{
${ }^{1}$ A coleta e a gravação foram iniciadas no dia 17 de fevereiro de 2003 e os nossos registros finalizados no dia 19 de maio de 2003.
} 
da Mata Atlântica e de um córrego. Nesse lado esquerdo, pode-se observar, ainda, a existência de várias casas grandes e confortáveis e, na rua anterior à escola, localiza-se um condomínio cuja maioria das casas pode ser definida como "casas confortáveis". Do lado direito, mais próximo ao lixão, as casas são menores e indicam um quadro de grande pobreza. Ademais, no interior do lixão, também encontramos moradias e podemos observar barracos feitos de madeira e papelão, onde muitas famílias moram ou guardam o material coletado. Dessa comunidade de contrastes sociais, culturais e ecológicos, advém a maioria dos alunos que frequenta a escola, alguns oriundos de comunidades próximas, como os bairros Caramujo e Ititioca.

As aulas da turma ocorriam às segundas-feiras em três tempos seguidos de 45 minutos. Assim, foi filmado um total de 30 horas-aula, embora tenhamos estado presentes no campo por 50 horas, ao longo dos meses de fevereiro, março, abril e maio de 2003.

O professor não recebeu nenhum treinamento ou indicativo de como deveria organizar as suas aulas; não interferimos na escolha do conteúdo e nem na forma como esse seria ensinado aos alunos. Pedimos que o professor organizasse suas aulas de forma habitual. Participaram delas aproximadamente 35 alunos. A sala de aula filmada atendia alunos do $4^{\circ}$ ciclo do Ensino Fundamental na faixa etária de 13 a 16 anos. Com vistas aos indicativos etários propostos por Habermas, acreditamos que, ao procedermos à pesquisa de campo nessa turma, poderíamos identificar a construção do processo de argumentação. Nesse direcionamento, para o qual a própria teoria habermasiana nos indica, os alunos que compõem a turma preenchem o requisito de idade adequada e estão estabelecendo ou já estabeleceram a capacidade de se colocar na terceira pessoa.

\section{A argumentação}

Nesta seção, estabelecemos com quais referenciais teóricos dialogamos para pensar o processo argumentativo na História ensinada. Nesse sentido, começamos com Goulart (2007, p. 2), que aproxima a teoria bakhtiniana da argumentação, construindo um diálogo com o autor e afirmando que enunciar é argumentar:

Parto do pressuposto de que é possível conceber, a partir da concepção de linguagem do autor, que enunciar é argumentar, tendo como horizonte as seguintes premissas:

(1) A argumentatividade da linguagem é inerente ao princípio dialógico, já que todo enunciado é produzido intencionalmente na direção do Outro, no movimento da interminável cadeia de enunciações.
(2) Enunciar é agir sobre o Outro, isto é, enunciar extrapola a idéia de compreender e responder enunciados.

Ao escolhermos as palavras de nossos enunciados/gêneros do discurso, segundo Bakhtin, partimos das intenções que presidem o seu todo. A situação social mais imediata e o meio social mais amplo determinam a estrutura da enunciação, em que as palavras são orientadas em função do interlocutor, do auditório social.

$O$ auditório social a que nos remetemos neste artigo é a sala de aula de História. O professor, nessa perspectiva, tem uma situação social definida, ou seja, a intenção de ensinar História, e, por conseguinte, seus argumentos orientam-se para essa finalidade, o seu aparato de saberes está focado nessa intencionalidade, o esforço argumentativo canalizado para esse fim.

Os vários saberes, seja da História, da profissão ou do auditório social, constituem um processo polissêmico e interativo na constituição argumentativa de seus enunciados. "O princípio dialógico é básico para a sua concepção de linguagem; é o princípio constitutivo de todo discurso. O dialogismo é desse modo, a condição de sentido do discurso, a ligação entre a linguagem e a vida social." (GOULART, 2007, p. 2). Dessa forma, conceber enunciação como espaço de argumentação é perceber que essa ação está permeada pelo espaço social, político e cultural em que o enunciado é proferido e pela intencionalidade que o sujeito tem ao proferir.

Não é qualquer enunciado ou qualquer forma de enunciação que podemos caracterizar como típica de uma "aula de História", e não é qualquer aula de História que podemos definir como espaço de enunciação argumentativa, uma vez que cada ator no processo de enunciação possui um papel e uma legitimação dada e certificada pelo grupo social em que o processo argumentativo é estabelecido.

Bakhtin destaca a profunda diferença entre duas categorias de palavras, a palavra de autoridade e a palavra internamente persuasiva. A palavra autoritária - religiosa, política, moral, a palavra do pai, dos adultos, dos professores, entre outros - não necessita de persuasão interior para a consciência, pois já a encontramos unida à autoridade; logo, exige de nós o reconhecimento e a assimilação. A força do argumento dessa palavra está ligada ao valor/peso que a fortalece e a sustenta, construído no passado hierárquico.

A palavra internamente persuasiva, por sua vez, carece de autoridade, sendo determinante para o processo da transformação ideológica da consciência individual. A palavra persuasiva interior é comumente metade nossa, metade de outrem. Tem produtividade criativa, no sentido de que pode reorganizar as palavras de nossos discursos em novos contextos, ao ingressar num 
inter-relacionamento tenso, e mesmo conflituoso, com outras palavras internamente persuasivas. (GOULART, 2007, p. 4).

A aula possui vários atores, sendo que o professor, nesse espaço de ação, possui um papel e uma função que o imbuem de autoridade. $\mathrm{O}$ ato de ensinar pode ou não possibilitar a constituição de uma argumentação internamente persuasiva (GOULART, 2007 , p. 4), entretanto, exerce tradicionalmente um papel vinculado à autoridade.

Destacamos ainda a possibilidade de aproximação das reflexões encaminhadas por Goulart (2007) com a teoria da ação comunicativa. Na perspectiva habermasiana, a pretensão de validez da argumentação, estabelecida em um espaço dialógico de encontro entre iguais, será colocada em xeque e, pela argumentação, se estabelecerá sua validade, ou a construção de uma nova validez, ou a rejeição total da pretensão inicial. O uso da autoridade, em uma perspectiva autoritária e coercitiva, é vista pelo teórico como uma ação estratégica, que visa a um fim não baseado no entendimento, mas sim na manipulação e na coação.

Para Habermas (2002), o argumento é o instrumento pelo qual as pretensões de validez são apresentadas e confrontadas. Na concepção de ação comunicativa habermasiana, os falantes, quando discordam do ponto apresentado, ou melhor, de uma questão pretensamente apresentada como verdadeira, analisam e julgam-na à luz da racionalidade processual, pela ação do diálogo argumentativo. Todos os componentes da ação argumentativa, na sua forma reflexiva, estão em igualdade de conhecimento e oportunidade de fala.

Por meio de argumentações, o caráter cooperativo das disputas em torno do melhor argumento se esclarece por uma finalidade relativa a uma função que é constitutiva para esses jogos de linguagem; os participantes querem se convencer mutuamente. Ao mesmo tempo que prosseguem o agir cotidiano comunicativo, se orientam, do nível reflexivo das exigências de validez tematizadas, para como diante do objetivo do entendimento, porque um proponente só pode ganhar o jogo quando convence seus oponentes da correção de sua exigências de validez. (HABERMAS, 2002, p. 65).

O espaço de argumentação reflexivo, a nosso ver, se estabelece no processo de inter-relação em que tanto o professor como os alunos estão em uma atitude de escuta mútua e de reorganização do enunciado argumentativo, visando o entendimento e a construção coletiva de uma pretensão de validez. Ou, dentro de uma perspectiva bakhtiniana, professor e alunos constroem a palavra internamente persuasiva em um processo constante de significação e validez.
Desse modo, cada enunciado é um elo da cadeia complexa de outros. Se, por um lado, o enunciado do locutor já contém o germe da resposta, por outro, o processo de compreensão de enunciados envolve a orientação do ouvinte em relação a ela, contextualizando-a, levando este a produzir contrapalavras ao enunciado do locutor. Este movimento ativo de enunciação dá-se na apreensão do tema dos enunciados. O autor chama de tema o sentido completo de cada enunciação e, com esse conceito, possibilita entender, principalmente do ponto de vista ideológico, diferenças sutis de significação em enunciados aparentemente semelhantes. (GOULART, 2007, p. 5).

O ensino de História possui um repertório temático pré-estabelecido, que tem como base o currículo historicamente construído. Em relação ao currículo, gostaríamos de salientar que não estamos operando com uma visão dicotômica do mesmo como fato ou como prática. Nessa perspectiva, o currículo está em constante significação, atravessado pelos sentidos em construção e permeado pelo mundo da vida e pelas contingências sociais que o formam.

[...] o currículo seria o espaço-tempo de interação entre culturas. Usando a terminologia de nossas coleções Modernas, em que as culturas são vistas como repertórios partilhados de sentidos, poderíamos enunciar um sem número de culturas presentes no currículo. (MACEDO, 2006, p. 106).

Nessa perspectiva, o currículo está em constante significação, sendo atravessado pelos sentidos em construção, permeado pelo mundo da vida e pelas contingências sociais que o formam.

A temática da enunciação do professor sofre os constrangimentos típicos do ato de ensinar e também as esferas discursivas ${ }^{2}$ exercem um poder de cerceamento sobre os argumentos do professor. Ao argumentar, o professor está dialogando com o auditório social presente - os alunos -, com a comunidade potencial em que a escola está inserida - Secretaria de Educação, direção da escola, responsáveis e poder religioso, jurídico, econômico, etc. -, com suas escolhas historiográficas e de ensino, com concepções de História do senso comum trazidas pelo aluno para o espaço argumentativo, isto é, com o mundo da vida. "Nas salas de aula, a tensão entre linguagens sociais do cotidiano e linguagens sociais sistematizadas como áreas de conhecimento deve aparecer por meio de diferenças nas construções composicionais interligadas aos valores dos enunciados." (GOULART, 2007, p. 7).

\footnotetext{
2 Usamos a perspectiva bakhtiniana, pois cada esfera que apresentamos - História, historiografia, ensino de História, História ensinada, currículo, etc. - são espaços de enunciados, constituem-se como múltiplos gêneros textuais e com elementos que os distinguem entre si.
} 
A linguagem historiográfica exerce um papel, se não fundamental, importante no espaço de aprendizagem da História ensinada, agindo de forma estruturante no argumento construído pelo professor.

[...] considero que a escola deva levar os sujeitos a aprender diferentes linguagens sociais de referência: da Ciência, da Matemática, da História, entre outras, para que compreendam outros modos de ler o mundo, outras esferas da vida social. Cada uma destas se constitui historicamente como uma textualidade, isto é, como uma organização discursiva que apresenta e explica a realidade, envolvendo objetos, fenômenos, procedimentos, relações tempo-espaço, entre outros aspectos. (GOULART, 2007, p. 6).

Assim, a História ensinada é atravessada não só pelas questões disciplinares relacionadas à historiografia, mas também pelo veículo em que a ciência História se manifesta e constitui sua materialidade. $O$ enunciado, nessa perspectiva, situa-se em um pano de fundo sociocultural e seu cenário se relaciona diretamente com a ação discursiva.

O enunciado está repleto dos ecos e lembranças de outros enunciados, aos quais está vinculado no interior de uma esfera comum da comunicação verbal. O enunciado deve ser considerado acima de tudo como uma resposta a enunciados anteriores dentro de uma dada esfera (a palavra 'resposta' é empregada aqui no sentido lato): refuta-os, confirma-os, completa-os, baseia-se neles, supõe-nos conhecidos e, de um modo ou de outro, conta com eles. Não se pode esquecer que o enunciado ocupa uma posição definida numa dada esfera da comunicação verbal relativa a um dado problema, a uma dada questão, etc. (BAKHTIN, 2000, p. 316).

Percebemos a palavra como múltipla, polissêmica e intersubjetiva. O espaço da História ensinada estaria nessa perspectiva em uma "arena polifônica", em uma "arena de luta", onde se confrontam culturas letradas nos eventos argumentativos, perpassados por questões culturais e ideológicas, ou seja, o ensinado é situado.

Um signo não existe apenas como parte de uma realidade; ele também reflete e refrata uma outra. Ele pode distorcer essa realidade, ser-lhe fiel, ou apreendê-la de um ponto de vista específico, etc. Todo signo está sujeito aos critérios de avaliação ideológica (isto é: se é verdadeiro, falso, correto, justificado, bom, etc.). O domínio do ideológico coincide com o domínio dos signos: são mutuamente correspondentes. Ali onde o signo se encontra, encontra-se também o ideológico. Tudo que é ideológico possui valor semiótico. (BAKHTIN, 2002, p. 32).

A História também traz consigo signos próprios, signos dos seus saberes e fazeres, entrecruzando-se com a História ensinada e habitando, dessa forma, os argumentos que se desenvolvem na sala de aula e na construção de sentido inerente a esse fazer.

A situação de aula, especialmente aulas em que se privilegiam a conversa, o debate e a discussão, torna o discurso de autoridade flexível, internamente persuasivo, utilizando a classificação de Bakhtin. Essa possibilidade parece estar associada à qualificação pelo professor do discurso dos alunos, à disposição para ouvi-los, reconhecendo-os como interlocutores e produtores de conhecimento. (GOULART, 2007, p. 7).

Nessa perspectiva, pensar o espaço da sala de aula como "lócus" argumentativo é um desafio pedagógico para o professor na produção de sentido histórico e na desnaturalização da realidade conforme o senso comum. A nosso ver, a função epistemológica essencial da História ensinada desafia o professor a buscar meios e estratégias para que o aluno olhe com estranheza para o que comumente é naturalizado e, em muitas das vezes, dogmatizado.

\section{História ensinada e a construção de sentido}

Busca-se, nesta seção, dialogar mais estreitamente com estudiosos do currículo, na interface da História ensinada, pois temos como horizonte a questão do saber do professor como uma ação racionalizada, destinada a um fim.

Para atingir essas finalidades pedagógicas inerentes ao seu trabalho, o professor deve tomar certas decisões em função do contexto em que se encontra e das contingências que o caracterizam (a manutenção da ordem na sala de aula, a transmissão da matéria, etc.). Ora, tomar decisões é julgar. Esse julgamento se baseia nos saberes do professor, isto é, em razões que o levam a fazer esse ou aquele julgamento e a agir em conformidade com ele. (TARDIF, 2007, p. 208).

Nesse viés, o professor é um sujeito ativo em seu fazer; suas ações em sala de aula possuindo uma intencionalidade e baseando-se em uma racionalidade que guia suas escolhas e ações conscientes e inconscientes. Destacamos a expressão "História ensinada", ato de construção do conhecimento do professor, a qual se estabelece e se corporifica no ato do "dar aula", no espaço da sala de aula, e que requer do sujeito professor ações e saberes de diversas naturezas e origens.

[...] o saber não é uma coisa que flutua no espaço: o saber dos professores é um saber deles e está relacionado com a pessoa e a identidade profissional, com a sua experiência de vida e com sua história profissional, com os outros atores escolares na escola, etc. Por isso, é necessário estudá-lo relacionando-o com esses elementos constitutivos do trabalho docente. (TARDIF, 2007, p. 11). 
O saber do professor está situado em uma perspectiva histórica, cultural, social e filosófica, revelando suas concepções de mundo, tempo, Educação, ensino e História, e construindo uma face intersubjetiva da História ensinada. Dessa maneira, as escolhas historiográficas eleitas pelo professor também são um marcador dessa História ensinada.

Monteiro (2007b, p. 103) nos ajuda a compreender essa questão, aqui considerada relevante ao se pensar História ensinada como uma ação do professor no espaço da "sala de aula de História":

A História, diferentemente das matemáticas, que possuem uma definição acadêmica muito clara, apresenta diferentes perspectivas de inteligibilidade - História positivista, dos Annales, marxista e das análises macroeconômicas, Nova História, e de composições, que se complementam frequente, a partir de diferentes formas de definição dos eixos de análises: temática - História política, História social, História econômica, História cultural; geopolítica (História do Brasil, História da América, História da Europa, História do Extremo Oriente, etc.), cronológica (Antiguidade, Idade Média, Idade Moderna, Idade Contemporânea, Tempo Presente, etc.) ou espacial (global, nacional, e regional).

Essa característica suscita, de imediato, uma questão de alguma complexidade: qual História utilizar como referência acadêmica para se contrastar com o saber a ensinar? (MONTEIRO, 2007b, p. 103).

Buscou-se também compreender o lugar da disciplina História no currículo e seu perfil no espaço educacional.

O que caracteriza o universo escolar é a relação entre as culturas, relação essa atravessada por tensões e conflitos. Isso se acentua quando as culturas crítica, acadêmica, social e institucional, profundamente articuladas, tornam-se hegemônicas e tendem a ser absolutizadas em detrimento da cultura experiencial, que, por sua vez, possui profundas raízes socioculturais. (MOREIRA; CANDAU, 2003, p. 156).

Nessa perspectiva, a cultura escolar perpassa a História ensinada na própria concepção de História, na própria cultura letrada presente na historiografia acadêmica, na historiografia presente nos livros didáticos e na concepção de história da vida que habita o senso comum. Essas múltiplas culturas se fazem presentes e desafiam o professor no ato de ensinar.

O cultural não pode, na perspectiva que defendo, ser visto como fonte de conflito entre diversas culturas, mas como práticas discriminatórias em que a diferença é produzida. Isso significa tentar descrever o currículo como cultura, não uma cultura como repertório partilhado de significados, mas como lugar de enunciação. (MACEDO, 2006, p. 105).
Nossa afirmação de transversalidade da cultura está baseada na perspectiva de que os espaços, tanto da oralidade como da escrita, estão impregnados da mesma, pois pensamos a sociedade contemporânea ocidental que tem em sua identidade constitutiva uma faceta assentada no grafocentrismo. Esse, como tal, se relaciona com a perspectiva cultural que define as faces do mundo da vida.

$O$ ato de ensinar só se faz significativo quando $o$ ato de aprender se constitui. Dessa forma, a reflexão sobre os processos de ensino e aprendizagem se faz necessária e fundamental para a construção da identidade profissional e da possibilidade de repensar sua própria formação. Nesse sentido, a colaboração do aluno e a sua parceria são fundamentais para o ensino de História e de qualquer disciplina.

Essa dimensão social pedagógica se mostra nesse fenômeno educativo que é fundamental, se é sempre possível manter os alunos "presos" fisicamente numa sala de aula, mas é impossível levá-los a aprender sem obter, de uma maneira ou de outra, seu consentimento, sua colaboração voluntária. A fim de aprender, os alunos devem tornar-se, de uma maneira ou de outra, os atores de sua própria aprendizagem, pois ninguém pode aprender em lugar deles. Transformar os alunos em atores, isto é, em parceiros da interação pedagógica, parece-nos ser a tarefa em torno da qual se articula e ganham sentido todos os saberes do professor. (TARDIF, 2007, p. 221)

Tardif (2007) reflete sobre a racionalidade que fundamenta o saber do professor, destacando que não é qualquer processo de racionalidade que pode ser vinculado ao saber da experiência. Essa racionalidade está baseada na função primeira e fundante da profissão docente - o ensinar, isto é, o objetivo do fazer que mobiliza os saberes do professor. Em primeiro lugar, o fundamental é levar o aluno a compreender e aprender determinado conteúdo ou conceito, os quais fazem parte da História e são recontextualizados na cultura escolar, materializando as correlações de força presentes no espaço de ensino - seja esse formal ou não. Dessa forma, os conteúdos eleitos na História ensinada revelam uma faceta da História e, ao mesmo tempo, silenciam outras tantas histórias.

A História ensinada tem um papel social e pedagógico e, como tal, produz, como já afirmamos, um conhecimento que se materializa na prática, dificultando sua compreensão e estabilidade, visto que o ato de ensinar se constitui na emergência do espaço da sala de aula. A construção de um conhecimento que transpassa o espaço físico da escola e o espaço conceitual da História é o combustível motriz da História ensinada, como Monteiro (2007c, p. 120) nos ajuda a compreender no trecho a seguir: 
Visões, concepções que articulam conteúdos e métodos, saberes e práticas, saberes a ensinar e saberes sobre o que, por sua vez, expressam valores e a dimensão educativa estruturante. Falas, expressões dos saberes dos docentes sobre os saberes ensinados, expressões do saber escolar, conteúdos pedagogizados.

Nessa direção, situada no espaço do entre saberes e dos fazeres dos professores (MONTEIRO, 2007b), a História ensinada é permeada pelas questões da cultura escolar e, assim, situa-se no mundo da vida pelas contingências que atravessam o ensinado. O professor, por exemplo, atua consciente e inconscientemente sobre sua ação. O ensinado é fruto de elementos tanto macro como micro no espaço da sala de aula e de saberes oriundos de múltiplos espaços de formação, reflexão e de vida.

O que caracteriza o universo escolar é a relação entre as culturas, relação essa atravessada por tensões e conflitos. Isso se acentua quando as culturas crítica, acadêmica, social e institucional, profundamente articuladas, tornam-se hegemônicas e tendem a ser absolutizadas em detrimento da cultura experiencial, que, por sua vez, possui profundas raízes socioculturais. (MOREIRA; CANDAU, 2003, p. 156).

Além disso, a validação do saber historicamente construído impregna o argumento constituído pelo professor, isto é, nem todo argumento poderá ser usado na construção do sentido pedagógico da História ensinada: há compromissos sociais e educacionais embutidos no ensinar.

A articulação entre Epistemologia e Linguagem tem como objetivo abrir pistas para pensar os saberes em geral, e os saberes históricos em particular, como práticas sociais e discursivas produtoras de verdades e de sentidos nos diferentes níveis de problemática em que estão envolvidos. Essa abordagem permite trabalhar de forma articulada as dimensões explicativas e interpretativas do conhecimento. (GABRIEL, 2003, p. 36).

As "verdades" e os "sentidos" se estabelecem no processo de negociação, na racionalidade processual constituída. Como Habermas define, pretensões de validez são validadas ou destituídas de valor no espaço argumentativo e, desse modo, a História ensinada traz consigo elementos das diversas esferas que a constituem, além dos argumentos constituídos nas negociações de sentido defendidas pelo professor com a pretensão de validez que ele enuncia em sua ação de ensino. O argumento é, portanto, a linha que junta as pretensões de validez e possibilita a materialização de um todo harmônico ou não. Quando esse processo de negociação e construção de sentido não se realiza, observa-se uma não aceitação das pretensões apresentadas e muitas vezes uma surdez coletiva. Assim, o professor não ouve os argumentos proferidos pelos alunos e vice-versa, não se estabelecendo uma ação dialógica e ocorrendo turnos de falas paralelas.

Na seção posterior, foram analisados episódios de argumentação estabelecidos em uma sala de aula de História. Buscou-se, na análise, dar um corpo ao que foi argumentado durante a escrita deste artigo.

\section{Novo olhar sobre antigos episódios}

Nesta seção, foram escolhidos, para se "olhar novamente", três episódios. Salienta-se que foram modificadas as divisões episódicas que constavam na dissertação, ou seja, os episódios foram novamente divididos para assim produzirem sentido em nossa perspectiva de análise. Assistimos novamente aos vídeos, exercício que foi muito importante em nossa reflexão e construção argumentativa.

\section{Episódio}

Este episódio marcou a apresentação da temática que seria tratada no bimestre.

Professor: 1. A matéria que eu estou trazendo no primeiro bimestre, o que é isso, uma coisa chamada posse e uma coisa chamada propriedade.

2. Para definir posse e propriedade, devemos partir de uma coisa anterior, partir da sociedade em que a gente vive.

3. A gente vive numa sociedade onde tudo se compra e tudo se vende. Tudo na sociedade em que a gente vive pode ser comprado e pode ser vendido. Entre aspas! Tudo em linhas gerais pode ser comprado pode ser vendido. Como se chama esse tipo de sociedade?

O professor iniciou o episódio definindo o tema "A matéria que eu estou trazendo no primeiro bimestre, o que é isso, uma coisa chamada posse e uma coisa chamada propriedade". Ele indicou, de forma geral, quais elementos constituiriam os enunciados que seriam proferidos durante o bimestre, apresentando a temática direcionadora dos enunciados.

O professor tentou aproximar os alunos de sua pretensão de validez, ao construir uma igualdade temporal, indicando que sua explicação partiria do presente - devemos partir de uma coisa anterior, partir da sociedade em que a gente vive. Continuou seu processo argumentativo estabelecendo uma generalização em relação à sociedade contemporânea: tudo na sociedade em que a gente vive pode ser comprado e pode ser vendido. Essa afirmação foi o estopim de um processo argumentativo denso a nosso ver.

A afirmação trouxe um argumento de igualdade dupla: 1) que o professor vive a mesma realidade 
que os alunos; 2) que essa realidade é percebida por todos da mesma forma. Tal pretensão não foi verdadeira e os alunos contra-argumentaram em diversos momentos, destituindo a validade da afirmação proferida pelo professor.

Em relação à analogia, Monteiro (2005, p. 341) afirma:

Este recurso, utilizado freqüentemente pelos docentes sem maiores reflexões, vem ao encontro de demandas do campo educacional como forma de viabilizar a aprendizagem, através de superação do estranhamento causado por processos e relações sociais desconhecidas pelo aluno.

Observamos que as generalizações e aproximações do professor tiveram em si uma finalidade: tornar o conteúdo compreensível ao aluno, construindo um sentido histórico, isto é, buscando uma relação temporal com o tema proposto e aproximando o passado do presente em que os alunos vivem. Aproximar o ensinado da realidade vivida pelo aluno é o grande movimento desse episódio, pois o professor acredita que, partindo da realidade que o aluno vive, ele pode compreender o conteúdo de História.

O passado não se repete, ele somente existe discursivamente. Dessa maneira, para reconstruir o passado, o historiador utiliza um instrumental discursivo que possibilita a sua explicação e a sua compreensão, como a utilização de analogias, generalizações e aproximações sociais dos acontecimentos vividos e experimentados pelo leitor. Busca, assim, produzir sentido e significação sobre o passado narrado. Dessa forma, essa esfera discursiva - a historiografia - impacta os argumentos tecidos pelo professor e sua estética discursiva.

O professor, para realizar a aproximação do conceito - propriedade e posse -, construiu generalizações e analogias, visando estabelecer uma ligação do mundo da vida dos alunos com o conteúdo ensinado. Então, lançou-se mão das estratégias pedagógicas utilizadas no episódio a fim de construir uma compreensão histórica e assim promover o aprendizado.

\section{Episódio}

Professor 1. Isso, sociedade de consumo, tudo pode ser consumido nessa sociedade em que a gente vive. Pois bem, é dentro dessa sociedade de consumo que a gente vai ter posse e propriedade, depois a gente vai ver essas coisas ao longo da História. Vai ver que a propriedade e a posse tiveram sempre o mesmo caráter, valor que tem hoje na sociedade em que a gente vive.

2. Vocês concordam comigo que nas sociedades de consumo tudo pode ser comprado, tudo pode ser vendido?
Alunos 3. Concordo (EM CORO).

Professor 4. Vocês vão concordar comigo, ou não; que nem sempre tudo que a gente consome, que nem sempre tudo que a gente compra, nem sempre é necessário para vida. Vocês concordam comigo?

Aluno C 5. Eu concordo também.

Aluno A 6. Eu concordo.

Professor 7. Por quê?

Aluno $\mathrm{C}$ 8. O senhor está falando, é mais inteligente é esperto, é o professor, eu concordo.

Alunos (Risos)

Professor 9. (O PROFESSOR RI) Queria saber por que nem tudo que a gente compra é uma necessidade nossa?

10. O que você compra e não é uma necessidade sua?

O professor iniciou o episódio destacando sua intenção: "Pois bem, é dentro dessa sociedade de consumo que a gente vai ter posse e propriedade, depois a gente vai ver essas coisas ao longo da História". Anunciou o procedimento pedagógico que iria utilizar, pretendendo analisar os conceitos de posse e de propriedade em sua continuidade histórica. Nesse mesmo turno de fala, ele afirmou - "Vai ver que a propriedade e a posse tiveram sempre o mesmo caráter, valor que tem hoje na sociedade em que a gente vive". Ao fazer essa afirmação, ele igualou processos históricos diferentes e planificou a ação histórica, correndo o risco de naturalizar questões tão complexas como propriedade e posse, que, ao longo da História, tiveram significações distintas e papéis sociais e políticos diferenciados.

A construção explicativa do professor salientou uma manutenção e estabilidade histórica da propriedade e da posse. Esse argumento pode estabelecer nos alunos uma pretensão de validez, que, diferentemente de desnaturalizar concepções estabelecidas no senso comum, age como solidificadora do mesmo.

O sentido a ser construído foi tecido pelo professor seguindo o mesmo caminho do episódio anterior, ou seja, aproximar o fato histórico da realidade vivida pelos alunos. Nesse processo de construção de sentido, ele teceu suas argumentações buscando o diálogo com os alunos e estabelecendo que o mundo da vida que os cerca está presente no conteúdo ensinado.

Nos turnos de 3 a 8 , observou-se um reconhecimento coletivo de que o discurso do professor estava imbuído de autoridade. O aluno C ironizou a pergunta do professor: "O senhor está falando, é mais inteligente é esperto, é o professor, eu concordo." O aluno identificou o professor como o detentor 
de um determinado poder e, dessa forma, sua palavra, "recoberta" de autoridade, necessita de persuasão interior, pois se une à autoridade. (GOULART, 2007, p. 4).

A pergunta do professor - "Vocês concordam comigo que nas sociedades de consumo tudo pode ser comprado, tudo pode ser vendido? - Por quê?" - buscou a persuasão interior, uma ação de cooperação e de entendimento entre ele e a turma, tentando, por conseguinte, estabelecer cumplicidade e cooperação.

O riso do professor produziu na turma um encontro maior que as suas palavras. Essa ação inaugural lançou uma aproximação da turma com o professor, a qual foi se estabelecendo gradativamente ao longo do bimestre. Todavia, neste trabalho, essa construção não foi observada, visto que demandaria uma análise muito maior do que a que se propôs fazer e que o espaço-tempo deste artigo nos permite.

\section{Episódio}

Professor 1. Olha, espera aí... O que a gente vai consumir por necessidade, o que a gente vai consumir por desejo?

2. Eu quero ter, vamos por aí, um iate. É uma necessidade minha ou é um desejo?

3. Eu vou comprar uma...

Aluno F 4. Um celular.

Professor 5. Um celular, espera aí, espera aí (Alguns ALUNOS TÊM CELULARES E OS USAM DE FORMA QUE SEJAM VISTOS.).

Aluno G 6. Celular é uma necessidade. (ELA ESTÁ COM CELULAR SOBRE A MESA)

Professor 7. Celular é desejo nosso ou necessidade?

8. Sem celular, algum de vocês é capaz de viver?

Alunos 9. Eu sou... (EM coro)

Alunos 10. Eu não... (EM coRo) ****

Aluno E 11. Eu vou dizer uma coisa do celular, qualquer hora que a gente quer ligar, liga.

Professor 12. Posso falar?

Aluno E 13. Pode falar.

Professor 14. Tô perguntando o que é um celular. É um desejo seu ou uma necessidade sua?

Aluna E 15. Acho que é os dois.

Professor 16. A única forma que você tem de falar com uma pessoa é pelo celular?

Aluno $\mathrm{E} \quad$ 17. Não tem o outro... é... é.... pode ser do outro telefone, o convencional.

Aluno $\mathrm{E}$ 18. O lugar que não tem um orelhão. Mas essas pessoas que moram no mato, não tem nenhum telefone. Se eu estiver em perigo, vou usar o celular.
Professor 19. Aí você tá falando que sua vida... você vai viver em constante... que a sua vida vai correr perigo a toda hora e a todo lugar...

Professor 20. Casa, escola ....

21. Temos ideias que essas necessidades básicas são iguais para todo mundo.

22. Vamos ver que vai variar muito pouco as necessidades das pessoas. Tá certo?...

23. Tem determinadas coisas que sem elas as pessoas não vivem...

24. A gente deseja coisas diferentes e precisamos de coisas semelhantes...

25. Diga um desejo seu...

O episódio inteiro é marcado pela diferença de percepção do que é desejo e necessidade entre o professor e o aluno E. O processo argumentativo desse episódio destituiu de valor a argumentação anterior proposta pelo professor no episódio I, no qual ele parte da premissa de que todos nós vivemos na mesma sociedade. Pela argumentação final do episódio III, podemos perceber que a realidade em que o aluno $E$ está inserido não é idêntica a do professor.

O diálogo, nesse episódio, possuiu uma forte marca da autoridade do professor e de seus critérios de valor, apresentando o que é válido e permitido por ele na construção do sentido histórico que estava sendo tecido. Observa-se também que os argumentos tecidos não seguiram uma linearidade "racional", eles se constituíram nesse labor incerto que é a sala de aula, construindo argumentos híbridos e ambivalentes, de sentidos situados e múltiplos.

O aluno categorizou o celular como necessidade e argumentou com a manutenção do mais essencial, "a vida": "O lugar que não tem um orelhão. Mas essas pessoas que moram no mato não têm nenhum telefone. Se eu estiver em perigo, vou usar o celular." Preservar a vida, que está em constante perigo, basta para afirmar, categoricamente, que o celular é uma necessidade básica. Além disso, junto a essa afirmação, há implícito o desserviço que o setor público presta às comunidades periféricas e de menor poder aquisitivo: "O lugar que não tem um orelhão. Mas essas pessoas que moram no mato não têm nenhum telefone." O aluno teceu seu argumento em diálogo com a realidade que o cerca, seguindo a indicação que o próprio professor apontou para organização do argumento - o que é básico para vida. Mesmo assim, a perspectiva apresentada não foi aceita, pois ela não foi compreendida pelo professor e, dessa forma, foi destituída de validez.

O professor contra-argumentou salientando que, para o celular ser uma necessidade, segundo o argumento da aluna, a vida correria um perigo constante. Assim, é importante reforçar que a escola 
está localizada em uma comunidade considerada pela população local como violenta e esse pressuposto social, a meu ver, qualifica o argumento da aluna como válido e a definição de celular como necessidade, uma pretensão aceita. Mas o professor desqualificou esse argumento - pudemos observar que ele balançou a cabeça em negação e seguiu a aula iniciando um novo episódio.

A atitude do professor, mais que a fala, está imbuída de um discurso de autoridade. Em um primeiro momento, tal professor buscou ser persuasivo chamando os alunos para apresentarem seus argumentos e percepções pertinentes ao conteúdo apresentado, todavia, diante do argumento da aluna, o qual não corroborou com os sentidos pretendidos, ele lança mão de sua autoridade e exerce seu poder modificando o encaminhamento das enunciações.

Macedo (2006, p. 105) nos ajuda a pensar o episódio em questão:

Julgo necessário esclarecer que não vejo o currículo como um cenário que as culturas lutam por legitimidade, um território contestado, mas como uma prática cultural que envolve, ela mesma, a negociação de posições ambivalentes de controle e resistência.

A atitude do professor, nesse episódio, apresentou uma forte ambivalência entre o argumento persuasivo e o de autoridade. A História ensinada caminha por um mar de incertezas em que intenções e ações nem sempre refletem uma a outra. A argumentação do professor, nesses episódios, apresenta um caminhar incerto e ambivalente a nosso ver, próprio do fazer em sala de aula que mescla várias realidades e diferentes percepções do mundo da vida.

Ao terminar o episódio, ele reconduziu o debate e ignorou o argumento do aluno. Observamos que, nessa dinâmica, o argumento do aluno foi segregado e as contingências sociais que o levaram a afirmar que celular era necessidade, destituídas de valor pelo professor; pois, de seu lugar de autoridade "legítima", cala o argumento que desqualifica a pretensão apresentada e defendida.

Nessa perspectiva, "não se pode esquecer as experiências de interação entre culturas têm sido muito marcadas por segregação e guetização, ou seja, pela tentativa de fixação de sentidos e de inviabilização da cultura como espaço-tempo de enunciação da diferença". (MACEDO, 2007, p. 106).

O sentido que o professor buscou fixar estava calcado em suas percepções de mundo e de seus próprios conceitos de que o celular não é uma necessidade básica. Diante da violência em que vivemos na atualidade e na possibilidade iminente de estarmos circundados pelo conflito, inclinamo-nos a compreender e a aceitar a pretensão de validez da aluna. Salienta-se, porém, que nossa investigação foi realizada em 2003 e a realidade belicosa do Rio de Janeiro era muito mais guetizada que agora.

Vale ressaltar que compreendemos como central no fazer do professor o ensinar. Em nosso caso, no caso da História ensinada, suas forças se movem para a construção de um sentido na História e, como "um" sentido, estabelece-se em "seu" ponto de vista. O professor como autoridade busca, nesse labor professoral, encaminhar os argumentos a validar sua pretensão. Como "autoridade", exerce esse lugar destacando e, às vezes, calando argumentos contrários e contraditórios aos seus processos explicativos e aos sentidos em construção conduzidos no processo de ensino.

O dar aula se faz no inusitado que a sala de aula apresenta. Assim, o fazer do professor muitas vezes caminha por essa ambivalência e hibridização argumentativa. Os trajetos dos argumentos muitas vezes se fazem por momentos de escuta e surdez, tecendo seus argumentos e construindo sentidos múltiplos - sentidos esses que, na pesquisa, percebemos como contraditórios e antagônicos. Porém, não podemos esquecer que o fazer se constitui pelo império do inédito e na emergência do cotidiano.

\section{Breves conclusões}

Neste trabalho, não se buscou analisar novamente todos os episódios eleitos em nossa dissertação. Objetivou-se, sim, fazer um exercício de aproximação entre uma pesquisa de campo e os estudos do campo do currículo, linguagem e cultura.

Compreende-se que nossa análise foi breve, mas acreditamos ser possível notar que olhar a sala de aula de História com as lentes do currículo, da cultura e da linguagem mostra-se promissor e desafiante, visto que percebemos, em vários momentos, que o que extravasa é a nossa percepção, a nossa história de vida, e, "habermasianamente" falando, as nossas pretensões de validez, trazendo com elas o mundo da vida que nos constitui.

Em relação às argumentações do professor, podemos compreender que elas dialogam com o mundo da vida que o estrutura enquanto pessoa e professor, e com as relações sociais e de poder que constituem seu horizonte discursivo. É inegável que sua compreensão sobre o argumento do aluno e a estruturação de seu próprio argumento está permeada das pretensões de validez que o constituem em relação à História ensinada e à Educação. A organização e constituição de seus argumentos apresentam uma ambivalência inerente à posição de "poder parcial" que o professor ocupa no ensinado. Esse 
poder parcial mescla a palavra de autoridade, a palavra internamente persuasiva e a condição primeira do magistério: o ensinar.

Tendo esse recorte teórico como lente, compreendemos que, ao ensinar História, o professor constrói seu discurso, buscando apresentar uma concepção de História e uma pretensão de validez sobre o passado que deverá ser apreendido pelos alunos. Além disso, esse professor organiza os argumentos em uma cadeia complexa, que traz em si uma possibilidade responsiva, tanto sua para o desdobramento do argumento como do aluno em suas possíveis participações e compreensão. Nesse processo de identificação e construção de sentido, o professor transita por momentos em que a palavra visa persuadir o aluno, e momentos em que essa palavra é revestida de autoridade e de seu lugar de poder na hierarquia da sala de aula. Dessa forma, compreendemos a construção de sentido na História ensinada como um processo ambivalente e híbrido que se constitui na dinâmica do tempo-espaço do fazer.

O exercício feito foi o refletir sobre a argumentação, buscando, nas vozes dos estudiosos, a construção de instrumental discursivo de análise em uma perspectiva dialógica. Nesse processo argumentativo, trouxemos algumas pretensões de validez e tentamos deixar claro, em nossa construção, o exercício de argumentação, buscando um enlace entre os elementos teóricos estudados e o campo de investigação no qual estivemos durante o mestrado. $\mathrm{Na}$ verdade, não sabemos se conseguimos validar nossas pretensões, cabendo ao leitor aceitar, refutar ou reconstruir coletivamente a pretensão apresentada. Ademais, não negamos que a escolha de nosso repertório visava um auditório específico - professores e academia -, mas gostaríamos de salientar que tentamos firmemente exercitar o processo argumentativo de nossa pretensão de validez.

\section{Referências}

BAKHTIN, M. Estética da criação verbal. 3. ed. São Paulo: Martins Fontes, 2000.

BAKHTIN, M.; VOLOCHINOV, V. N. Marxismo e Filosofia da Linguagem. São Paulo: HUCITEC/ ANNABLUME, 2002.

GABRIEL, C. T. A. Um objeto chamado história: a disciplina de história nas tramas da didatização. 2003. 385 f. Tese (Doutorado em Educação) - Faculdade de Educação, Pontifícia Universidade Católica do Rio de Janeiro, Rio de Janeiro, 2003.

GOULART, C. M. Enunciar é argumentar: analisando um episódio de uma aula de História com base em Bakhtin. Pro-posições, Campinas, v. 18, n. 3 (54), p. 93-107, set./dez. 2007.
HABERMAS, J. Agir comunicativo e razão destranscendentalizada. Rio de Janeiro: Tempo Brasileiro, 2002.

MACEDO. E. Currículo: política, cultura e poder. Currículo sem Fronteiras, v. 6, n. 2, p. 98-113, jul./dez. 2006.

MONTEIRO, A. M. F. da C. Entre o estranho e o familiar: o uso de analogias no ensino de história. Cadernos Cedes, Campinas, v. 25, n. 67, p. 333-347, set./ dez. 2005. DOI: 10.1590/S0101-32621998000300001

. Professores de História: entre saberes e práticas. Rio de Janeiro: Mauad X, 2007a.

Ensino de História: entre história e memória. In: SILVA, G. V. da.; SIMÕES, R. H. S.; FRANCO, S. P. (Org.). História e educação: territórios em convergência. Vitória: UFES/PPGH, 2007b. p. 59-80.

Narrativa e narradores no ensino de história. In: MONTEIRO, A. M. F. da C.; GASPARELLO, A. M.; MAGALHÃES, M. S. (Org.). Ensino de História: sujeitos, saberes e práticas. Rio de Janeiro: Mauad X: FAPERJ, 2007c.

MOREIRA, A. F. B.; CANDAU, V. M. Educação escolar e cultura(s): construindo caminhos. Revista Brasileira de Educação, Rio de Janeiro, n. 23, p. 156-168, maio/ ago. 2003. DOI: 10.1590/S1413-24782003000200012

TARDIF. M. Saberes docentes e formação profissional. 8. ed. Petrópolis: Vozes, 2007.

Recebido em 10/03/2010

Versão final recebida em 20/03/2011

Aceito em 05/04/2011 